\title{
Cutaneous Asthenia in a Domestic Cat (Felis silvestris catus)
}

\author{
Ana Cláudia de Souza Andrade ${ }^{1}$, Laisa Marina Rosa Rey ${ }^{1}$, Isabela Carvalho dos Santos ${ }^{1}$, \\ Sarah Gabriella Delallo Charnovski ${ }^{2}$, Diogo Czornobai ${ }^{3}{ }^{3}$, Lariane Souza Silva ${ }^{3}$, \\ Jéssica Crespi Sabadin ${ }^{3} \&$ Daniela Dib Gonçalves ${ }^{1}$
}

\begin{abstract}
Background: Cutaneous asthenia or Ehlers-Danlos syndrome is an inherited and rare disease. This infirmity is from an autosomal mutation that influences the collagen synthesis of the carrier. Thus, its skeleton, formed of fibers, is structurally defective. The disease is characterized by hyperelasticity and skin fragility, leading to lesions throughout the skin. The lesions may manifest in specific places or in a generalized way, being more frequent in the limbs, neck, and back. This disease does not have a specific treatment, only management care to avoid new traumas.

Case: A 3-year-old male castrated, no defined race cat, was attended at one veterinary clinic with a history of intense itching. The rapid tests for feline immunodeficiency virus (FIV) and feline leukemia virus (FeLV) were negative. On physical examination, infestation by fleas, lesions all over the body, and skin hyperelasticity were observed. Topical treatment for ectoparasites as well as for body wounds was established. After the treatment, he returned without itching, but with the complaints of new lesions that did not heal. The patient underwent a total shearing to facilitate the treatment of the skin, and then he underwent blood tests, biochemistry, hormonal tests, and ultrasound, which showed no suggestive changes for hyperadrenocorticism and diabetes mellitus. His clinical signs, besides not matching with these diseases, also did not indicate skin fragility due to his history of age and balanced diet. The confirmation of the cutaneous asthenia syndrome was acquired through biopsy of skin fragment, in which it was observed disarray of collagen fibers, hypertrophy, and fibroblast hyperplasia, together with the rate of extensibility of the skin where the value reached the mark of $27.5 \%$. Throughout the hospitalization, it was noted the progression of the disease with the appearance of new lesions, where there was no bleeding and they appeared even with the patient wearing padded clothes. Its progression lasted one year until the patient's euthanasia. Discussion: For the disposal of diabetes mellitus and hyperadrenocorticism as causes of the appearance of lesions by the body in the patient, he was submitted to the suppression tests with dexamethasone, in which he presented normality, in the biochemical examination it was dosed with fructosamine and glucose. The fructosamine was in the reference value, but the glucose was slightly altered, this increase may have been a result of stress at the time of blood collection. In addition to the patient not showing specific clinical signs such as polyphagia, polyuria, polydipsia, and weight loss, these are characteristic clinical signs of the disease. For the diagnosis of Ehlers-Danlos syndrome, histological examination, and calculation of the skin extensibility index were used, where the results obtained confirmed the suspicion. This genetic anomaly has no treatment, being progressive, so only environmental management is done to mitigate the appearance of the lesions and provide animal welfare. This case report contributes to aggregating the scientific literature in the area of veterinary medicine since skin asthenia is a rare disease and when its extent is total it becomes even more atypical. The availability of this article will provide a vision of palliative treatment for other cases, demonstrating the progressive nature of the lesions and the methods of diagnosis.
\end{abstract}

Keywords: cat, collagen deficiency, ehlers-danlos syndrome, hyperelastic, skin. 


\section{INTRODUCTION}

Skin asthenia syndrome is a rare and incurable disease that affects several species of animals such as dogs, cattle, sheep, horses, rats, cats [1,5]. Cases of the syndrome in dogs and cats are rare. Among these rare reports, it is observed that some breeds may have a higher occurrence. In cats, the reports show that it occurs in long hair breeds such as Persian and Burmese [13]. It presents as the main clinical manifestation the skin hyperelasticity, a hereditary characteristic that can be autosomal dominant or recessive, varying with the organization of collagen fibers presented $[9,12,14]$.

The genes involved in the syndrome are responsible for the proteins that compose the synthesis or degradation of collagen type I $[1,4,10]$. This deficiency in the protein is what originates the defect, which is the main characteristic of the fragility of the conjunctive tissue $[4,8]$.

The lesions may manifest in specific places or in a generalized way, being more frequent in the limbs, neck, and back [12]. The clinical manifestations are cutaneous and are characterized by skin extensibility, but may occur in joint areas $[11,16]$.

One of the diagnostic methods can be performed by the skin extensibility index and the histopathological examination that will show structural changes in collagen [2].

Due to the lack of scientific literature on the subject, this work aimed to report the case of total skin asthenia in a domestic cat, demonstrating the management measures adopted in order to prevent skin trauma and thus promote quality of life for the bearer of the syndrome.

\section{CASE}

A 3-year-old male castrated, no defined short hair race cat, weighing $4 \mathrm{~kg}$, was treated at Di Gatto ${ }^{\circledR}$ veterinary clinic, in Cascavel, PR, Brazil. The animal was already vaccinated (Rabies, Panleukopenia, Rhinotracheitis, Calicivirus, Chlamydiosis), and fed with super-premium cat food and with access to the backyard of the house. The tutor reported that the patient presented intense itching, excessive licking, and neck and back injuries that had not healed for 3 months, having been previously medicated by other professionals.

In the physical examination, the hyperelastic skin was noted when assessing the turgor of the skin, in which it did not present the usual resistance of a normal skin when pulled, the change was observed throughout the body. The lesions were not mucopurulent or flaking, they were located behind the ears and near the neck of the animal, they were visibly caused by friction of the nails when scratching the region, due to the previous infestation by ectoparasites (fleas), which healed slowly after their extinction. The lesions on the body were superficial and without apparent reason.

Treatment for fleas with Vectra ${ }^{\circledR 1}$ (VO), hair removal was performed to facilitate the topical treatment of the lesions, and access to the external environment was restricted.

After 15 days, the patient returned to the clinic complaining of new skin lesions that did not heal. The patient stayed in the clinic for environmental control for 15 days and in this period, it was observed the lack of itching, but the animal continued to present lesions without signs of healing. Because of the lesions on the body, the patient was submitted to exams to diagnose the basic cause of the disease.

The diagnostic plan included a complete blood count (CBC), biochemical serum panel, dexamethasone suppression test, skin fragment histology, abdominal region ultrasonography, and SNAP test of FIV and FeLV (Alere ${ }^{\circledR 2}$ FIV Ac/FeLV Ag), the differentials, in this case, being capillary fragility, hyperadrenocorticism and diabetes mellitus.

In complementary tests, the $\mathrm{CBC}$ showed a small change in the value of leukocytes $(23,500 / \mu \mathrm{L}$ [5,500 - 19,500]). The biochemical panel expressed the values according to the normal reference values. The suppression test with dexamethasone was within the normal range for the species, with the glucose value of $226 \mathrm{mg} / \mathrm{dL}$ and the fructosamine value of $0.2 \mathrm{mg} / \mathrm{L}$. The rapid tests for feline immunodeficiency virus (FIV) and feline leukemia virus (FeLV) were negative.

At abdominal ultrasonography, no alterations were found. The biopsy of the animal skin fragment was performed with the sample measuring $8.0 \mathrm{~cm}$ by $5.0 \mathrm{~cm}$ by $1.0 \mathrm{~cm}$, microscopic areas of healing with hypertrophy and fibroblast hyperplasia were noted. In the dermis, a disorganization of the collagen fibers was observed, as well as a variation in size, shape, and increased space between the fibers.

In Masson's Trichrome coloration ${ }^{3}$, it was evidenced the variation of size, shape, an increase of space between the collagen fibers, and a reddish coloration 
in the center and blue in the periphery of the collagen fibers, assuming the cutaneous asthenia anomaly.

Finally, the patient was submitted to the skin measurement test, the extensibility index, in order to evaluate the percentage of its elasticity. From the occipital ridge measurement to the base of the tail, the value of $40 \mathrm{~cm}$ was obtained, the value of the body length measurement (Figure 1) and the fold at the level of the lumbar dorsum, the value of $11 \mathrm{~cm}$ was obtained, a vertical measurement (Figure 2). The result of the calculation for the extensibility index was $27.5 \%$, signaling a probable diagnosis for EhlersDanlos syndrome.

During hospitalization, the patient was monitored for 15 days. The evolution of his clinical picture was noted, by visualizing the worsening of age-old and newly acquired lesions in the dermis. These lesions obtained a significant size in such a way as to cause contact of the environment with skin traumas, and thus prophylaxis with cephalexin [Lexin ${ }^{\circledR 4}$ - 75 mg was started, twice a day, for 14 days and orally].

After skin biopsy, measurement tests and progressive evolution of the case confirmed the patient's diagnosis as Ehlers-Danlos Syndrome. To soften and prevent the appearance of new lesions in the animal, a cushioned suit was used, which proved to be useful for an improvement in its condition (Figure 3).

Due to the progressive characteristic of the disease, after 1 year of clinical follow-up, the lesions already spread throughout the body. Thus, the patient was referred for euthanasia.

\section{DISCUSSION}

At the end of all the data presented, it was demonstrated the confirmation of the cutaneous asthenia syndrome, even more for its total extension by the patient's body. This article comes to foster knowledge about the disease and the methods adopted as therapeutic resources.

Clinical findings such as age, hyperelasticity, hyperdistension, skin fragility, body injuries, decreased resistance to skin traction, atrophic scars, and back injuries are characteristic of the pathology $[8,15,17]$.

Diabetes mellitus is associated with obesity and persistent hyperglycemia, the patient was not obese $(4 \mathrm{~kg})$ and in his biochemical examination, there was no change in the fructosamine, despite the small increase in glucose. [3]. Increased glucose may be related to

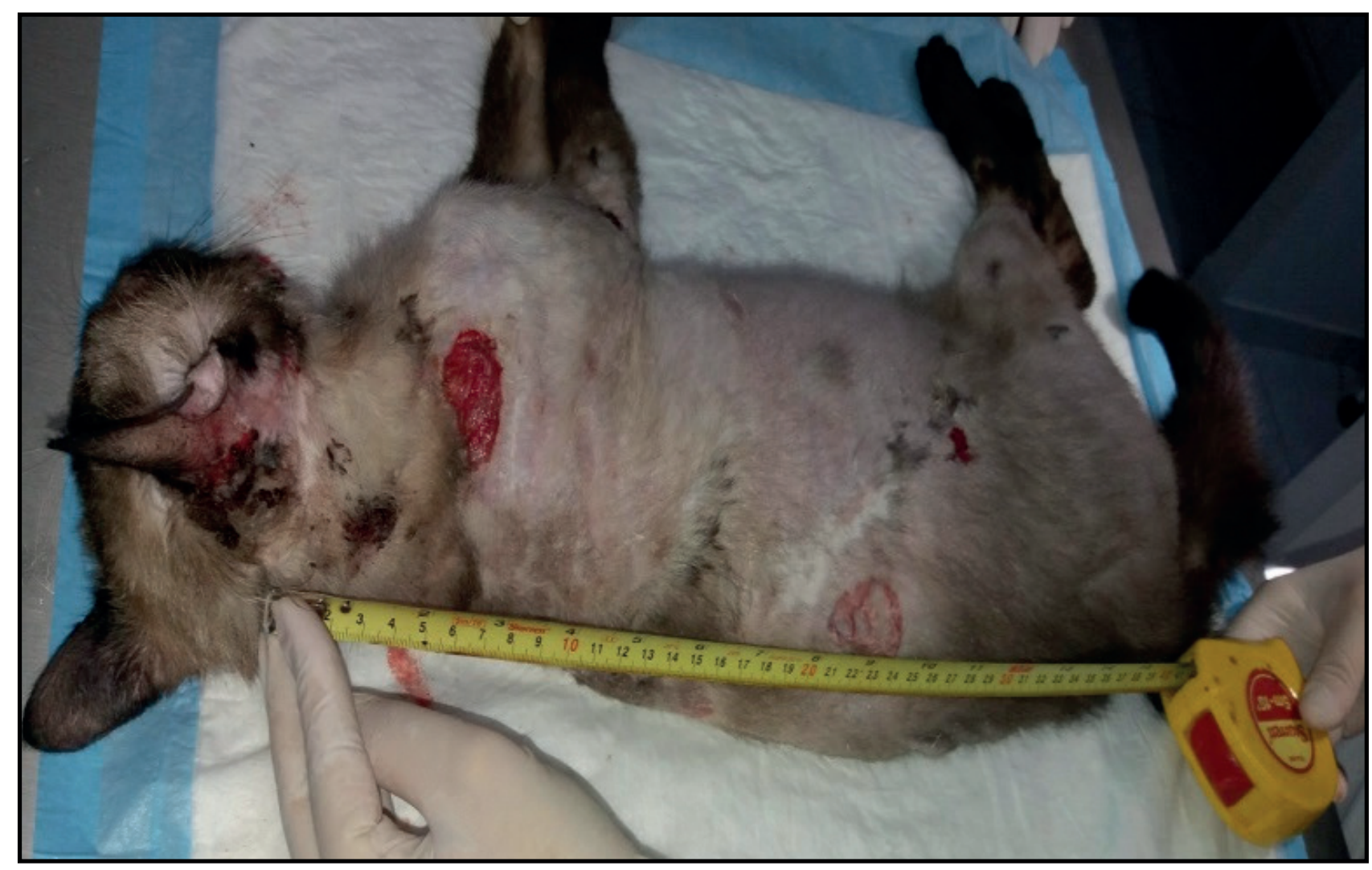

Figure 1. The value of the body length measurement $(40 \mathrm{~cm})$ was obtained from the occipital ridge measurement to the base of the tail of a 3 -year-old male castrated, no defined short hair race cat. 


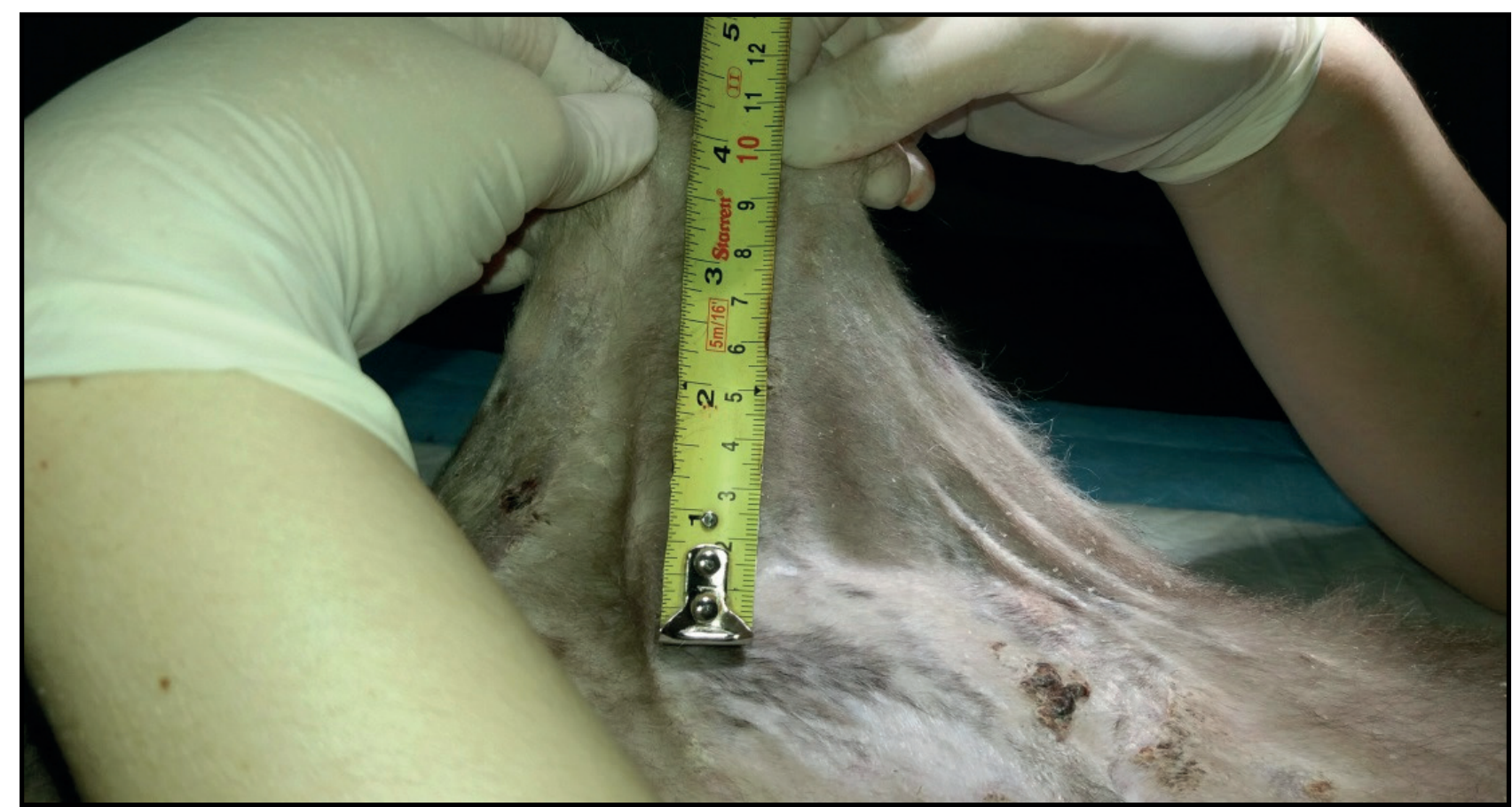

Figure 2. The value of a vertical measurement $(11 \mathrm{~cm})$ was obtained from the fold at the level of the lumbar dorsum of a 3-year-old male castrated, no defined short hair race cat.

increased cortisol caused by stress, it is observed by increased leucocytes in the patient's blood count (stress leucogram) [6].

Hyperadrenocorticism is also a rare disease in young cats, it originates from excess cortisol in the body and there are different reasons for this increase as adrenal tumors and pituitary tumors. The clinical signs of the patient in question did not fit this disease as polyphagia, polydipsia, polyuria, and weight loss. The excess of cortisol causes the loss of subcutaneous fat in the animal making the skin thinner, this fact

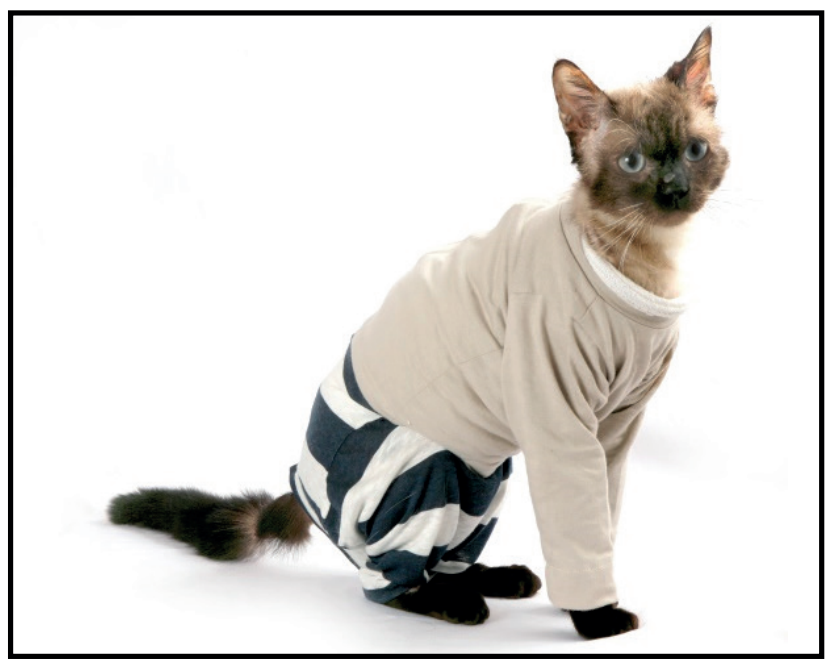

Figure 3. Treatment using padded clothing in a 3-year-old male cat. was also not found in the patient in question. At the ultrasonography, the adrenal glands were found with size, shape, contour, and echogenicity preserved. The dexamethasone suppression exam was found within normality, discarding the hyperadrenocorticism.

Skin fragility is an acquired syndrome characterized by thin skin that easily gives way after minimal trauma, but hyperextensibility of the skin is not observed in this syndrome, in this case, the skin elasticity was clearly seen, and then the extensibility index was performed, presented a value of $27.5 \%$, in which the normality value for cats is up to $19 \%$, besides the progressive evolution which is characteristic of the anomaly $[11,16]$.

Through CBC, biochemical, hormonal tests, and ultrasonography together with the clinical signs and progression of the disease was ruled out the possibility of the primary cause being associated with diabetes mellitus, hyperadrenocorticism, and skin fragility.

Through histopathological findings in the dermis of areas with hypertrophy and fibroblast hyperplasia, disorganization of the collagen fibers, and variation in size and shape, the collagen presents with variation in size and orientation of the bundles and fragmentation using Masson's Trichrome staining (Figure 4) $[7,16,17]$, the diagnosis of skin asthenia was confirmed. 


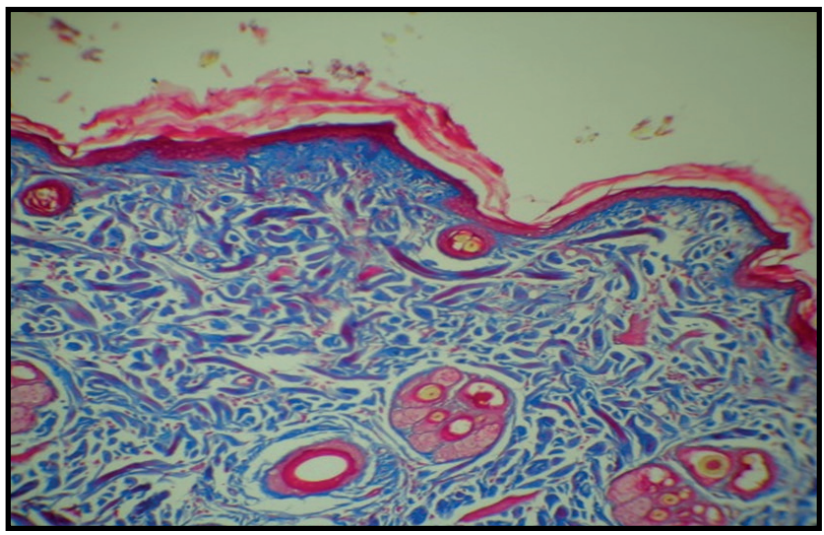

Figure 4. Histopathological findings in the dermis shows the skin with the blue colored collagen fibers and some reddish colored fibers [Masson's Trichrome staining].

The sum of clinical signs, complementary tests, extensibility index, histopathological examination, and the progression of the disease within 1 year, confirm the total cutaneous asthenia syndrome in the feline, in which it led to the generalized lesion by the body of the animal, thus opting for euthanasia due to lack of quality of life.

This case report contributes to the field of veterinary dermatology since skin asthenia is a rare disease and when its extent is total it becomes even more atypical. The availability of this article will provide a vision of palliative treatment for other cases, demonstrating the progressive nature of the lesions and the methods of diagnosis.

\section{MANUFACTURERS}

${ }^{1}$ Ceva Saúde Animal Ltda. São Paulo, SP, Brazil.

${ }^{2}$ Alere S.A. Maringá, PR, Brazil.

${ }^{3}$ Merck Sharp \& Dohme Saúde Animal Ltda. Barueri, SP, Brazil.

${ }^{4}$ Laboratórios Duprat Ltda. Rio de Janeiro, RJ, Brazil.

Acknowledgements. To CAPES, for granting the PROSUP school fee and to UNIPAR, for funding this research and to the feline tutors for their constant collaboration.

Declaration of interest. The authors report no conflicts of interest. The authors are the only ones responsible for the content and writing of this article.

\section{REFERENCES}

1 Alcalá C.O.R. \& Menezes N.C. 2016. Cutaneous Asthenia in Dog. MedVet Dermato - Revista de Educação Continuada em Dermatologia e Alergologia Veterinária. 4(12): 1-4.

2 Andrade S., Tostes R., Sanches O., Melchert A., Nogueira R. \& Valente S. 2008. Astenia Cutânea em Gato (Case Report). Revista Ciência Animal Brasileira. 9(2): 524-528.

3 Bertoldo J., Honda C., Amorin D., Almeida F., Prado A., Peregrino L., Gonçalves E.S., Guedes E., Viana J.A. \& Ferreira L.G. 2019. Fisiopatologia Do Diabetes Mellitus E Obesidade Em Felinos. Revista Agroveterinária do Sul de Minas. 1(1): 91-104.

4 Bicca E., Almeida F., Pinto G., Castro L. \& Almeida H. 2011. Classic Ehlers-Danlos syndrome: clinical, histological, and ultrastructural aspects. Brazilian Annals of Dermatology. 86(4 Suppl 1): S164-S147.

5 Days N.M. 2018. Allelic frequency of single nucleotide polymorphism c,2032>A in the PLOD1 gene, responsible for equine cutaneous fragility syndrome. 59f. Botucatu, SP. Dissertação (Mestrado) - Universidade Estadual Paulista, Faculdade de Medicina Veterinária e Zootecnia, Campus de Botucatu.

6 Gregório R.S. 2017. Relação entre a exposição a fatores ambientais estressantes e a Diabetes mellitus nos gatos. $73 f$. Lisboa, Portugal. Dissertação (Mestrado) - Universidade de Lisboa, Faculdade de Medicina Veterinária de Lisboa.

7 Harrison B., Sanniec K. \& Janis E. 2016. Collagenopathies-Implications for Abdominal Wall Reconstruction: A Systematic Review. Plastic and Reconstructive Surgery Global Open. 4(10): 1036. DOI: https://dx.doi.org/10.1097\% 2FGOX.0000000000001036

8 Hasen N., Foste S., Burrows A., Mackie J. \& Malik R. 2015. Cutaneous asthenia (Ehlers-Danlos-like syndrome) of Burmese cats. Journal of Feline Medicine and Sugery. 17(11): 954-963. DOI: https://doi.org/10.1177\%2F1098612X15610683

9 Matthews B.R. \& Lewis G.T. 1990. Ehlers-Danlos syndrome in a dog. The Canadian Veterinary Journal. 31(5): 389390.

10 Medleau L. \& Hnilica K.A. 2003. Doenças Congênitas. Dermatologia De Pequenos Animais: Atlas Colorido e Guia Terapêutico. São Paulo: Roca, pp.340-342.

11 Patterson D.F. \& Minor R.R. 1977. Hereditary fragility and hyperextensibility of the skin of cats. Laboratory Investigation. 37(2): 170-179. 
12 Tryon R.C., White S.D., Famula T.R., Schultheiss P.C., Hamar D.W. \& Bannasch D.L. 2005. Inheritance of hereditary equine regional dermal asthenia in Quarter Horses. American Journal of Veterinary Research. 66(3): 437-442. DOI: https://doi.org/10.2460/ajvr.2005.66.437

13 Valencia E.A.F. 2015. Diagnosis of Cutaneous astenia in a dog. A case report. 10f. Medellín, Colombia. Trabalho de Conclusão (Especialização) - Especialização em Medicina de Pequenas Espécies Animais, Escola de Medicina Veterinária, Faculdade de Ciências Agrárias, Universidade de Antioquia.

14 Valentin S.Y., Cortright C.C., Nelson R.W., Pressler B.M., Rosenberg D., Moore G.E. \& Scott-Moncrieff J.C. 2014. Clinical findings, diagnostic test results, and treatment outcome in cats with spontaneous hyperadrenocorticism: 30 cases. Journal of Veterinary Internal Medicine. 28(2): 481-487. DOI: https://doi.org/10.1111/jvim.12298

15 Vasconcelos E.A., Gurgel A.R. \& Pachaly J.R. 2010. Astenia cutânea canina: relato de caso. MEDVEP - Revista Científica de Medicina Veterinária. Pequenos Animais e Animais de Estimação. 8(25): 345-349.

16 White S.D., Affolter V.K., Schultheiss P.C., Bola B.A., Wessel M.T., Kass P., Molinaro A.M., Bannasch D.L. \& Ihrke P.J. 2007. Clinical and pathological findings in a HERDA-affected foal for 1.5 years of life. Veterinary Dermatology. 18(1): 36-40. DOI: https://doi.org/10.1111/j.1365-3164.2007.00562.x

17 Zanette F. \& Rossi C.N. 2015. Combinação atípica de alterações cutâneas, articulares e oftálmicas em cão com síndrome de Ehlers-danlos: relato de caso. Revista de Educação Continuada em Medicina Veterinária e Zootecnia do CRMV-SP. 13(3): 53. 